\title{
Substation Earthing Design
}

\author{
Akshay Patil \\ (Electrical and Electronics Engineering, Navrachana University, India)
}

\begin{abstract}
Successful operation of entire power system depends to a considerable extent on efficient and satisfactory performance of substations. Hence substations in general can be considered as heart of overall power system. In any substation, a well-designed grounding plays an important role. Since absence of safe and effective grounding system can result in mal-operation or non-operation of control and protective devices, grounding system design deserves considerable attention for all the substations. There are two primary functions of a safe earthing system. Firstly, ensure that a person who is in the vicinity of earthed facilities during a fault is not exposed to the possibility of a fatal electrical shock. Secondly, provide a low impedance path to earth for currents occurring under normal and fault conditions. The earthing conductors, composing the grid and connections to all equipment and structures, must possess sufficient thermal capacity to pass the highest fault current for the required time.
\end{abstract}

Keywords: Conductor, Earthing, Grid, Impedance, Thermal Capacity

\section{Introduction}

An electrical substation is a serioussource in a power system. Safe process of a substation appeals for a well-designed and properly installed grounding system. A well-designed grounding system will safeguard reliable performance of the substation over its entire service life.Decent grounding path of adequately low impedance certifies fast clearing of faults. The power system stability of system may affect if fault is persisted for a longer duration.Faster clearing thus advancestotal reliability. It also guarantees safety.A ground fault in equipment causes the metallic enclosure potential to rise above the 'true' ground potential. An improper grounding results in a higher potential and also results in delayed clearing of the fault (due to insufficient current flow). This arrangement is essentially dangerous because any person coming into contact with the enclosure is exposed to higher potentials for a time-consuming duration.Therefore, substation dependability and protection must be as 'built-in' as possible by worthy grounding scheme, which will turn to safeguard faster fault clearing and low enclosure potential rise.

Grounding system has to be safe as it is straight concerned with safety of individual's working within the substation. Chief purpose of this work is designing safe and cost effective grounding systems for HV / EHV substations situated at such locations where soil of the substation site is not uniform. Standard equations are used in the design of earthing system to get desired parameters such as touch and step voltage criteria for safety, earth resistance, grid resistance, maximum grid current, minimum conductor size and electrode size, maximum fault current level and resistivity of soil. By selecting the proper horizontal conductor size, vertical electrode size and soil resistivity, the best choice of the project for safety can be performed.Substation earthing system is primarily not only to deliver the protection of people working in the surrounding area of earthed facilities and equipment against danger of electric shock, but to uphold proper function of electrical system. Reliability and security are to be taken in contemplations as well as adherence to statutory obligations.

\subsection{Importance:}

The earthing system in a plant / facility is very important for a few reasons, all of which are related to either the protection of people and equipment and/or the optimal operation of the electrical system.

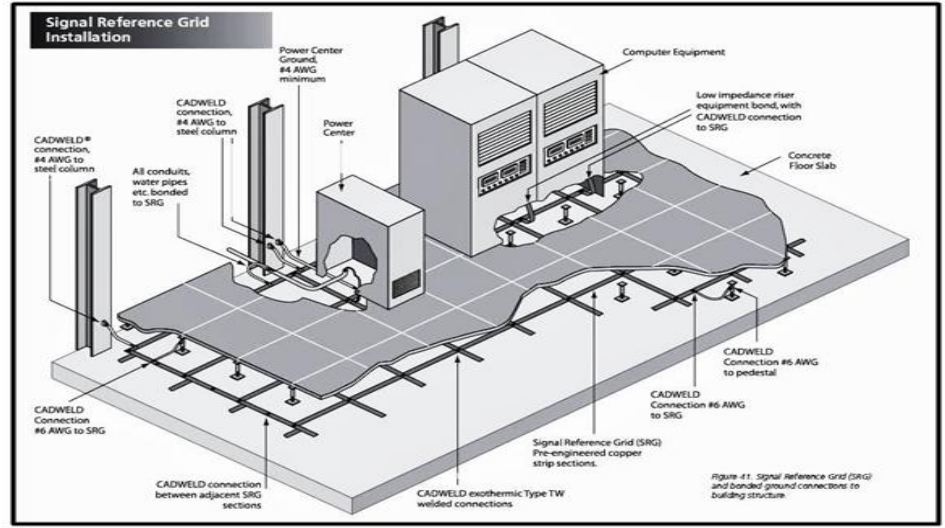

FIG. 1 HV Substation Earthing 
These include:

Equipotential bonding of conductive objects (e.g. metallic equipment, buildings, piping etc.) to the earthing system prevent the presence of dangerous voltages between objects (and earth).

- The earthing system provides a low resistance return path for earth faults within the plant, which protects both personnel and equipment.

- For earth faults with return paths to offsite generation sources, a low resistance earthing grid relative to remote earth prevents dangerous ground potential rises (touch and step potentials)

- The earthing system provides a low resistance path (relative to remote earth) for voltage transients such as lightning and surges / overvoltages

- Equipotential bonding helps prevent electrostatic build up and discharge, which can cause sparks with enough energy to ignite flammable atmospheres

- The earthing system provides a reference potential for electronic circuits and helps reduce electrical noise for electronic, instrumentation and communication systems.

- This calculation is based primarily on the guidelines provided by IEEE STD. 80 (2000), "Guide for safety in AC substation grounding".

\section{Earthing Standards}

There are a variety of national and international standards available, which provide empirical formulae for the calculation of earthing design parameters and shock potential safety limits.

- $\quad$ BS7354 - 1990 Code of Practice for Design of High Voltage Open Terminal Stations

- IEEE Std. 80-2000 IEEE Guide for Safety in AC Substation Grounding

- $\quad$ EATS 41-24 - Guidelines for the Design, Installation, Testing \& Maintenance of Main Earthing Systems in Substations.

\section{Terms Associated with Earthing:}

\subsection{Ground Potential Rise (GPR)}

The substation earth grid is used as an electrical connection to earth at zero potential reference. This connection is not ideal due to the resistivity of the soil within which the earth grid is buried.

During typical earth fault conditions, the flow of current via the grid to earth will therefore result in the grid rising in potential relative to remote earth to which other system neutrals are also connected.

This produces potential gradients within and around the substation ground area - this is defined as ground potential rise or GPR.

The GPR of a substation under earth fault conditions must be limited so that step and touch potential limits are not exceeded, and is controlled by keeping the earthing grid resistance as low as possible.

\subsection{Step, Touch, Mesh \& Transferred Potentials}

In order to ensure the safety of people at a substation, it is necessary to ensure that step and touch potentials in and around the substation yard during earth-fault conditions are kept below set limits.

These maximum permitted step and touch potentials are addressed within various national and international standards.

\subsection{Step Potential}

The step potential is defined as the potential difference between a persons outstretched feet, normally 1 metre apart, without the person touching any earthed structure.

\subsection{Touch Potential}

The touch potential is defined as the potential difference between a person's outstretched hand, touching an earthed structure, and his foot. A person's maximum reach is normally assumed to be 1 metre.

\subsection{Earthing System Design Considerations}

Conductors - a substation earthing grid will consist of an earthing system of bonded cross conductors.

The earthing conductors, composing the grid and connections to all equipment and structures, must possess sufficient thermal capacity to pass the highest fault current for the required time.

Also, the earthing conductors must have sufficient mechanical strength and corrosion resistance. It is normal practice to bury horizontal earthing conductors at a depth of between $0.5 \mathrm{~m}$ and $1 \mathrm{~m}$ - this ensures that the earth conductor has the following properties:

- Adequate mechanical protection

- It is situated below the frost line

- The surrounding earth will not dry out

1.6 Vertically Driven Earth Rods

Where there are low resistivity strata beneath the surface layer then it would be advantageous to drive vertical earth rods down into this layer - to be effective the earth rods should be on the periphery of the site. The length of the earth rod is chosen so as to reach the more stable layers of ground below. 
The earth rods would stabilise the earth grid resistance over seasonal resistivity changes at the grid burial depth. 1.7 Substation Fences

The earthing of metallic fences around a substation is of vital importance because dangerous touch potentials can be involved and the fence is often accessible to the general public.

Fence earthing can be accomplished in two different ways:

Electrically connecting the fence to the earth grid, locating it within the grid area or alternatively just outside Independently earthing the fence and locating it outside the earth grid area at a convenient place where the potential gradient from the grid edge is acceptably low.

\subsection{Other Substation Earthing}

The GPR at a substation is reduced by:

Overhead line earth wires which are connected to the substation earthing grid. This diverts part of the earth fault current to the tower footing earthing.

Cable entering and leaving the site.The armouring of such cables is usually earthed to the substation earthing grid at both ends. Part of the earth fault current will thus be diverted to a remote earthing grid via the cable armouring.

\section{Nomenclature and Given Data:}

\begin{tabular}{|c|c|}
\hline \multicolumn{2}{|c|}{ NOMENCLATURE } \\
\hline Symbol & Description \\
\hline$\rho$ & Soil Resistivity \\
\hline$\rho_{s}$ & Gravel Resistivity \\
\hline Iefs & Symmetrical Short Circuit Current \\
\hline$t_{s}$ & Duration of Earth Fault Current \\
\hline$h_{s}$ & Thickness of Crushed Gravel \\
\hline$h$ & Depth of Earth Grid \\
\hline$h_{o}$ & Reference depth of the Grid \\
\hline $\begin{array}{c}\alpha \\
\gamma\end{array}$ & Resistivity of Conductor Material \\
\hline$\rho_{\gamma}$ & Thermal co-efficient of resistivity at reference temperature \\
\hline$T_{m}$ & Max. allowable temperature in ${ }^{\circ} \mathrm{C}$ \\
\hline$T_{a}$ & Ambient temperature in ${ }^{\circ} \mathrm{C}$ \\
\hline Ko & $1 / \mathrm{a} 0$ or $1 / \mathrm{ar}-\mathrm{Tr}$ in ${ }^{\circ} \mathrm{C}$ \\
\hline$t_{c}$ & Duration of Current in $\mathrm{s}$ \\
\hline TCAP & thermal capacity per unit volume \\
\hline$A m m^{2}$ & Conductor cross section in $\mathrm{mm}^{2}$ \\
\hline$K$ & Reflection factor between different material resistivities \\
\hline$C s$ & Surface layer derating factor \\
\hline$E_{\text {step } 70}$ & Step Voltage for body weight of $70 \mathrm{~kg}$ \\
\hline$E_{\text {touch } 70}$ & Touch Voltage for body weight of $70 \mathrm{~kg}$ \\
\hline$E_{\text {step50 }}$ & Step Voltage for body weight of $50 \mathrm{~kg}$ \\
\hline$E_{\text {touch } 50}$ & Touch Voltage for body weight of $50 \mathrm{~kg}$ \\
\hline $\mathrm{n}$ & Number of parallel conductors \\
\hline $\mathrm{D}$ & Conductor Spacing \\
\hline Lp & Length of the conductor across perimeter \\
\hline $\mathrm{Nr}$ & No. of Ground Rods \\
\hline $\mathrm{Lr}$ & Length of Ground Rods \\
\hline LR & Total length of Ground Rods \\
\hline LT1 & Total length of buried conductor \\
\hline LT & Total length of buried conductors \& rods \\
\hline $\mathrm{Lx}$ & Maximum length of conductor in X-Axis \\
\hline Ly & Maximum length of conductor in Y-Axis \\
\hline $\mathrm{A}$ & Area of the Grid \\
\hline $\mathrm{R}_{\mathrm{g}}$ & Grid Resistance \\
\hline $\mathrm{I}_{\mathrm{g}}$ & Maximum grid current in $\mathrm{A}$ \\
\hline $\mathrm{D}_{\mathrm{f}}$ & Decrement factor for the entire duration of fault, given in $\mathrm{s}$ \\
\hline $\mathrm{Ki}$ & Corrective factor for current irregularity \\
\hline $\mathrm{Km}$ & Spacing factor for Mesh Voltage \\
\hline Kii & $\begin{array}{l}\text { Corrective weighting factor that adjusts the effect of inner conductors } \\
\text { on the corner mesh }\end{array}$ \\
\hline $\mathrm{Kh}$ & Corrective weighting factor that emphasising the grid depth \\
\hline Ks & Spacing factor for Step voltage \\
\hline
\end{tabular}


Substation Earthing Design

\begin{tabular}{|c|c|c|c|c|}
\hline \multicolumn{5}{|c|}{ GIVEN DATA } \\
\hline $\begin{array}{l}\text { Sr. } \\
\text { no. }\end{array}$ & Description & Notations & Unit & Value \\
\hline 1 & Soil Resistivity & $\rho$ & Ohm-M & 25 \\
\hline 2 & Gravel Resistivity & $\rho_{s}$ & Ohm-M & 3000 \\
\hline 3 & Symmetrical Short Circuit Current & Iefs & A & 40,000 \\
\hline 4 & Duration of Earth Fault Current & $t_{s}$ & $\mathrm{sec}$ & 0.5 \\
\hline 5 & Thickness of Crushed Gravel & $h_{s}$ & $\mathrm{~m}$ & 0 \\
\hline 6 & Depth of Earth Grid & $h$ & $\mathrm{~m}$ & 1.2 \\
\hline 7 & Reference depth of the Grid & $h_{o}$ & $\mathrm{~m}$ & 1 \\
\hline 8 & Resistivity of Conductor Material & ${ }_{\gamma}^{\alpha}$ & Ohm - M & 0.0032 \\
\hline 9 & Thermal co-efficient of resistivity at reference temperature & $\rho_{\gamma}$ & Ohm - M & 20.1 \\
\hline 10 & Max. allowable temperature in ${ }^{\circ} \mathrm{C}$ & $T_{m}$ & ${ }^{\circ} \mathrm{C}$ & 419 \\
\hline 11 & Ambient temperature in ${ }^{\circ} \mathrm{C}$ & $T_{a}$ & ${ }^{\circ} \mathrm{C}$ & 40 \\
\hline 12 & $1 / \mathrm{a} 0$ or $1 / \mathrm{a}_{\mathrm{r}}-\mathrm{T}_{\mathrm{r}}$ in ${ }^{\circ} \mathrm{C}$ & Ko & ${ }^{\circ} \mathrm{C}$ & 293 \\
\hline 13 & Duration of Current in $\mathrm{s}$ & $t_{c}$ & $\mathrm{~s}$ & 0.5 \\
\hline 14 & thermal capacity per unit volume & TCAP & $\mathrm{J} / \mathrm{cm}^{3 \circ} \mathrm{C}$ & 3.93 \\
\hline 15 & Conductor cross section in $\mathrm{mm}^{2}$ & $A m m^{2}$ & $\mathrm{~mm}^{2}$ & 415.08 \\
\hline 16 & Number of parallel conductors & $\mathrm{n}$ & -- & 12 \\
\hline 17 & Conductor Spacing & $\mathrm{D}$ & $\mathrm{m}$ & 2 \\
\hline 18 & Length of the conductor across perimeter & Lp & $\mathrm{m}$ & 69.5 \\
\hline 19 & No. of Ground Rods & $\mathrm{Nr}$ & -- & 12 \\
\hline 20 & Length of Ground Rods & $\mathrm{Lr}$ & $\mathrm{m}$ & 5 \\
\hline 21 & Total length of Ground Rods & LR & $\mathrm{m}$ & 60 \\
\hline 22 & Total length of buried conductor & LT1 & $\mathrm{m}$ & 248 \\
\hline 23 & Total length of buried conductors $\&$ rods & LT & $\mathrm{m}$ & 308 \\
\hline 24 & Maximum length of conductor in X-Axis & $\mathrm{Lx}$ & $\mathrm{m}$ & 25 \\
\hline 25 & Maximum length of conductor in Y-Axis & Ly & $\mathrm{m}$ & 10 \\
\hline 26 & Area of the Grid & $\mathrm{A}$ & $\mathrm{m}^{2}$ & 247.5 \\
\hline 27 & Decrement factor for the entire duration of fault, given in $\mathrm{s}$ & $\mathrm{D}_{\mathrm{f}}$ & & 0.415 \\
\hline
\end{tabular}

\section{Calculations:}

\section{Calculation Of $220 \mathrm{Kv}$ Bus Section}

\subsection{Size Of Earthing Conductor :}

$$
A m m^{2}=\frac{I}{\sqrt{\left(\frac{T C A P \times 10^{-4}}{t_{c} \alpha_{r} \rho_{r}}\right) \ln \left(\frac{K_{0}+T_{m}}{K_{0}+T_{a}}\right)}}
$$

$\mathrm{A}_{\mathrm{kcmil}}=819.37 \mathrm{kcmil}$

$\mathrm{Amm}^{2}=415.08 \mathrm{~mm}^{2}$

The size of conductor selected $=23.0 \mathrm{~mm}$

Diameter of the Grid Conductor $\mathrm{d}=0.02299 \mathrm{~m}$

\subsection{Touch \& Step Criteria:}

Reflection factor between different material resistivities

Surface layer derating factor $\quad C_{s}=\frac{0.09\left(1-\frac{\rho}{\rho_{s}}\right)}{2 h s+0.09} \quad K=\frac{\rho-\rho_{s}}{\rho+\rho_{s}}$

$\mathrm{C}_{\mathrm{s}}=0.01$

Therefore,

$$
\begin{gathered}
E_{\text {step } 70}=\left(1000+6 C \times \rho_{s}\right) \frac{0.157}{\sqrt{t}} \\
\quad \mathrm{E}_{\text {step } 70}=255.34 \text { Volts } \\
E_{\text {tounc } 70}=\left(1000+1.5 C \times \rho_{s}\right) \frac{0.157}{\sqrt{t}}
\end{gathered}
$$

$\mathrm{E}_{\text {touch } 70}=230.36$ Volts 


\subsection{Grid Resistance:}

$$
R_{s}=\rho\left[\frac{1}{L_{r}}+\frac{1}{\sqrt{20 A}}\left(1+\frac{1}{1+h \sqrt{20 / A}}\right)\right]
$$

$\mathrm{A}=$ Area of the Grid $=247.5 \mathrm{~m}^{2}$

$\mathrm{R}_{\mathrm{g}}=$ Grid Resistance $=0.74 \Omega$

\subsection{Maximum Grid Current:}

$$
I_{G}=D_{f} \times I_{g}
$$

$\mathrm{I}_{\mathrm{G}}=$ Maximum grid current in $\mathrm{A}=40,000$

$\mathrm{D}_{\mathrm{F}}=$ Decrement factor for the entire duration of fault, given in $\mathrm{s}=0.415$

$\mathrm{I}_{\mathrm{G}}=16600 \mathrm{~A}$

\subsection{Ground Potential Rise:}

GPR $=12287.2$ Volts $G P R=I_{G} \times R_{s}$

\section{Verification For Human Safety}

The safety to personnel is specified by IEEE 80, which requires limiting the development of electrical potential to dangerous value during earth fault current.

The regulation stipulates the following parameters to be within the permissible limit

a) Step Voltage (Foot to Foot Contact)

b) Touch Voltage(Hand to Foot Contact)

\subsection{Calculation For Actual Derived Step \& Mesh Voltage}

\section{Mesh Voltage:}

$$
\text { Emesh }(\text { Design })=\frac{\rho \times I_{o} \times K_{m} \times K_{c}}{L_{c}+\left[1.55+1.22\left(\frac{L_{r}}{\sqrt{L_{s}^{2}+l_{b p}^{2}}}\right)\right] \times L_{k}}
$$

$\mathrm{Ki}=$ Corrective factor for current irregularity

Where,

$$
K_{i}=0.644+0.148 n
$$

$\mathrm{n}_{\mathrm{a}}=7.1$

$\mathrm{n}_{\mathrm{b}}=1.050917456$

$\mathrm{n}_{\mathrm{c}}=1$ for square and rectangular grids

$\mathrm{n}_{\mathrm{d}}=1$ for square and rectangular grids and L Shaped grids

Therefore, $\mathrm{n}=7.48$

$\mathrm{K}_{\mathrm{i}}=1.75$

$$
\begin{aligned}
& K m=\frac{1}{2 \Pi} \ln \left[\frac{D^{2}}{16 h d}+\frac{(D+2 h)^{2}}{8 D d}-\frac{h}{4 d}\right]+\frac{K i i}{K h} \ln \left[\frac{8}{\Pi(2 n-1)}\right] \\
& K_{i i}=\frac{1}{(2 \times n)^{\frac{2}{n}}}
\end{aligned}
$$

Kii $=0.60$ and

Kii $=1.00$ with ground rods

$$
\sqrt{\left(1+\frac{h}{h o}\right)}
$$


$\mathrm{Kh}=1.48$

$\mathrm{Km}=0.57$

$\mathrm{E}_{\mathrm{mesh}}=1169.50$ Volts $($ Designed $)$

Calculated Mesh Voltage is lower than the Tolerable Touch Voltage.

HENCE SAFE

Step Voltage:

Voltage developed for step as per the earthing system proposed during full Earth fault current.

Where,

$$
\operatorname{Estep}(\text { Design })=\frac{\left[\left(K s \times K i \times \rho \times I_{G}\right)\right]}{\left[0.75 \times L_{c}+0.85 \times L_{R}\right]}
$$

$\mathrm{K}_{\mathrm{s}}=$ Spacing factor for Step voltage

$$
K s=\frac{1}{\Pi}\left[\frac{1}{2 h}+\frac{1}{D+h}+\left(\frac{1-0.5^{n-2}}{D}\right)\right]
$$

$\mathrm{K}_{\mathrm{s}}=0.388$

$$
K i=0.644+0.148 n
$$

$\mathrm{K}_{\mathrm{i}}=1.751772846$

$\mathrm{E}_{\text {step }}=1191.75$ Volts (Designed)

Calculated Step Voltage is lower than the Tolerable Step Voltage.

HENCE SAFE.

\section{Conclusion}

This paper has a focus on designing of a $220 \mathrm{kV} \mathrm{HV/LV} \mathrm{AC} \mathrm{substation} \mathrm{earthing} \mathrm{system.} \mathrm{The} \mathrm{results} \mathrm{for}$ earthing system are obtained by computational method. For earthing conductor and vertical earth electrode, mild steel are used. The step by step approach for designing a substation earthing system is presented. The various kinds of conductor sizes for earth equipment are mentioned in this paper. Construction of earthing grid is expressed in here. The step and touch voltages are dangerous for human body. Human body may get electric shocks from step and touch voltages. When high voltage substations are to be designed, step and touch voltages should be calculated and values must be maintained specified standard.Importance to be given to the transfer of Ground Potential rise (GPR) under fault conditions to avoid dangerous situations to the public, customer and utility staff. The values of step and mesh voltages obtained for $220 \mathrm{kV}$ substation are respectively 1191.75 Volt and 1169.50 Volt which are within the permissible limits.

\section{References}

[1]. IEEE guide for safety in AC Substation Grounding," IEEE 80-2000,pp.1-192.

[2]. IEEE std 81-1983," IEEE guide for Measuring earth Resistivity, Ground impedance, and earth surface potentials for a ground system"

[3]. IEEE, "IEEE Recommended Practice for Determining the Electric Power Station Ground Potential Rise and Induced Voltage From a Power Fault," IEEE Std 367-1996, 1996, pp. 1-125

[4]. Rao Sunil S., _Switchgear Protection and Power Systems‘. 12th edition, Khanna Publishers, New Delhi, 2007

[5]. International Journal of Advances in Engineering \& Technology, Jan. 2014. IJAET ISSN: 223119632597 Vol. 6, Issue 6, pp. $2597-$ 2605 Design of earthing systemfor HV/EHV AC substation (a case study of 400kV substaion at Aurangabad, India) Swapnil. G. Shah1 and Nitin. R. Bhasme2. 